los tratados con celecoxib, en comparación con los tratados con otros AINE; esta reducción fue mayor en los pacientes que no estaban tomando aspirina (73\%; IC95: 52 a $84 \%)$.

En resumen, este metaanálisis revela que el celecoxib es tan eficaz como los demás AINE en la $\mathrm{AR}$ y la artrosis, que posee una tolerabilidad y seguridad GI significativamente mayor que estos, $y$ que esta mayor seguridad GI sigue manifestándose incluso en pacientes tratados con aspirina. En opinión de los autores, los datos existentes no indican que se deba retirar el celecoxib en pacientes tratados con aspirina, al contrario de lo que han recomendado algunas autoridades. (Deeks JJ, Smith LA, Bradley MD. Efficacy, tolerability, and upper gastrointestinal safety of celecoxib for treatment of osteoarthritis and rheumatoid arthritis: systematic review of randomised controlled trials. BMJ 2002; 325:619-623).

\section{Inmunoterapia con Mycobacterium vaccae (SRL172) como adyuvante del tratamiento antituberculoso en pacientes infectados por el VIH}

Pese al tratamiento antituberculoso y a la buena respuesta clínica y microbiológica a la quimioterapia convencional de corta duración, las tasas de mortalidad de los pacientes con tuberculosis (TBC) infectados por el virus de la inmunodeficiencia humana (VIH) siguen siendo elevadas en el África subsahariana. Por consiguiente, hay una necesidad urgente de encontrar tratamientos que mejoren el desenlace clínico de la TBC en estos pacientes.

En un intento de modificar la respuesta inmunitaria, se ha estudiado la posible utilidad de la administración de inmunoterapia con Mycobacterium vaccae (SRL172). Los resultados de los estudios iniciales indicaron que este tratamiento podría ser útil. Como la vacuna es barata y fácil de administrar, se podría utilizar en los programas de control de la TBC en los países en desarrollo. Sin embargo, todavía no se han realizado ensayos clínicos formales para determinar si el SRL172 reduce la mortalidad de los pacientes con TBC infectados por el VIH.

El objetivo de este ensayo clínico aleatorizado, doblemente enmascarado, controlado con placebo, consistió en determinar si la inmunoterapia con una única dosis de SRL172 administrada como complemento de la quimioterapia antituberculosa convencional de corta duración mejora la supervivencia de adultos centroafricanos con TBC pulmonar e infectados por el VIH. La principal medida de eficacia fue la mortalidad por todas las causas. Como medidas secundarias se incluyeron la seguridad, la conversión de los cultivos a los 2 meses y los resultados bacteriológicos 12 meses después del comienzo de la quimioterapia antituberculosa.

El estudio se realizó entre septiembre de 1996 y octubre de 1998. Se consideraron elegibles todos los adultos diagnosticados de TBC pulmonar con frotis de esputo positivo. Los criterios de inclusión fueron: edad de 18 a 60 años; deseo de recibir la vacuna, cumplir la totalidad del tratamiento antituberculoso, acudir a las consultas de seguimiento durante 18 meses y someterse a pruebas de detección del VIH; domicilio identificable; ausencia de enfermedades graves que no fueran la TBC y esperanza de vida de 2 semanas como mínimo. Se excluyeron las embarazadas. Tras el examen inicial, todos los pacientes comenzaron a recibir quimioterapia antituberculosa convencional de corta duración (8 meses), siguiendo las normas de los respectivos programas nacionales de lucha contra la TBC. Aleatoriamente, los pacientes fueron asignados para recibir una sola inyección de $0,1 \mathrm{~mL}$ de SRL172 que contenía $10^{9}$ microorganismos muertos por calentamiento ( $M$. vaccae, cepa NCTC11659) o placebo. La inyección se administró a las 2 semanas del comienzo de la quimioterapia antituberculosa.

De los 1442 pacientes con TBC examinados inicialmente, 1229 fueron asignados aleatoriamente (1 079 en Lusaka y 150 en Karonga). Después de excluir a 84 pacientes por diferentes motivos, quedaron 1145 para el análisis, 760 de ellos positivos al VIH. De estos 760, 374 fueron asignados al tratamiento con SRL172 y 386 al tratamiento con placebo. Los dos grupos de tratamiento presentaban características similares, tanto entre los positivos como entre los negativos al VIH. El porcentaje de seguimiento a los 12 meses fue de $88 \%$ en ambos grupos de tratamiento.

Entre los pacientes VIH-positivos en los que se efectuaron cultivos a las 8 semanas, estos fueron negativos en 178 de $217(82,0 \%)$ tratados con SRL172 y en 209 de $239(87,4 \%)$ tratados con placebo $(P=$ $0,14)$. En los VIH-negativos, las cifras correspondientes fueron 88 de $112(79,0 \%)$ y 77 de $116(66,0 \%)$ $(P=0,06)$. La proporción de pacientes con cultivos negativos a los 12 meses fue similar con ambos tratamientos: $88 \%$ con SRL172 y $87 \%$ con placebo.

Entre los pacientes VIH-positivos, fallecieron 109 de 372 asignados al tratamiento con SRL172, lo cual representa una mortalidad de 19,5 por 100 personas-año (intervalo de confianza de 95\% [IC95]: 16,0 a 23,6), y 107 de 386 asignados al tratamiento con placebo, lo cual representa una mortalidad de 19,3 por 100 personas-año (IC95: 15,8 a 23,3). En el análisis de regresión de Cox estratificado por centro, la razón de riesgos instantáneos (hazard ratio) de muerte (SRL172/ placebo) fue de 1,03 (IC95: 0,79 a 1,35).

El SRL172 no causó acontecimientos adversos graves. 
De acuerdo con los resultados obtenidos, a pesar de ser segura y bien tolerada, la inmunoterapia con una única dosis de SRL172 como adyuvante de la quimioterapia antituberculosa convencional en adultos VIH-positivos con TBC pulmonar no tuvo efectos significativos sobre la mortalidad, la conversión del cultivo a los 2 meses ni los resultados bacteriológicos a los 12 meses. (Mwinga A, Nunn A, Ngwira B, Chintu C, Warndorff D, Fine P, et al. Mycobacterium vaccae (SRL172) immunotherapy as an adjunct to standard antituberculosis treatment in HIV-infected adults with pulmonary tuberculosis: a randomised placebo-controlled trial. Lancet 2002;360:1050-1055.)

\section{Sistemas de sujeción para niños en los automóviles}

En Canadá, los accidentes de tráfico constituyen la principal causa de muerte en la población infantil. El hecho de no usar sistemas de sujeción o de no usar el sistema adecuado se asocia frecuentemente a las muertes y lesiones por esta causa. Teniendo en cuenta estos datos, la información proporcionada por el médico a los padres acerca de la importancia del uso de sistemas de sujeción adecuados puede ser la actividad más importante para la promoción de la salud infantil. En este artículo el autor resume los conocimientos actuales sobre el uso de sistemas de sujeción para niños en los automóviles.

Las autoridades rodoviarias canadienses recomiendan cuatro tipos de sistemas de sujeción para niños, dependiendo del peso: 1) asientos de seguridad que miren hacia atrás para los niños de hasta $10 \mathrm{~kg}$ (aproximadamente 1 año); 2) asientos de seguridad que miren hacia delante para los niños de 10 a 18 o $22 \mathrm{~kg}$ (aproximadamente 4,5 años; 3) asientos elevados para niños de 22 a $27 \mathrm{~kg}$ (aproximadamente 8 años), y 4) uso del cinturón de seguridad en el asiento trasero del automóvil para niños de más peso. Estas cifras de peso son variables según los países.

El asiento trasero es el más seguro. Según un estudio, el ir sentado en el asiento trasero reduce en $36 \%$ el riesgo de muerte de niños implicados en accidentes mortales, independientemente del uso, o no, de sistemas de sujeción. Según otro estudio, el riesgo de sufrir lesiones graves o mortales es 1,7 veces menor (intervalo de confianza de 95\%: 1,6 a $2,0)$ cuando el niño va sentado en el asiento trasero que cuando va en el delantero. Otros estudios han estimado que el uso correcto de asientos de seguridad para niños reduce el riesgo de muerte en $71 \%$ y el riesgo de lesiones graves en $67 \%$, y que el uso de asientos de seguridad que miran hacia atrás reduce en $96 \%$ las lesiones en menores de 3 años.

La frecuencia del uso de sistemas de sujeción disminuye a medida que aumenta la edad de los niños. En Canadá, en 1997, dicha frecuencia fue de 96\% para los lactantes, de $91 \%$ para los niños de 1 a 4 años, y de 85\% para los de 5 a 15 años. En los Estados Unidos de América (EE. UU.), las cifras correspondientes fueron $85 \%, 60 \%$ y $65 \%$ en 1996 . El factor que mejor predice el uso de sistemas de sujeción para niños en accidentes mortales es el uso de dichos sistemas por el conductor del vehículo. Por otra parte, la frecuencia del uso inadecuado de estos sistemas ha oscilado entre 44 y $81 \%$ para los asientos de seguridad para niños, y entre 33 y $50 \%$ para los asientos elevados.

La American Academy of Pediatrics ha recomendado recientemente que los niños deben ir en asientos que miren hacia atrás durante el máximo tiempo posible, y al menos hasta que cumplan 1 año. Muchos de estos asientos están diseñados para niños de hasta $14 \mathrm{~kg}$. Esta posición es segura siempre que haya apoyo para la cabeza, y todavía no se han descrito casos de lesiones neurológicas catastróficas en niños sentados así.

La tríada completa de las lesiones producidas por los cinturones de seguridad consiste en equimosis de la pared abdominal, lesiones de las vísceras abdominales y fracturas vertebrales. Los niños son más propensos a estas lesiones porque a menudo el cinturón les queda grande y les pasa por el abdomen, en vez de por las caderas. Este problema se resuelve con los asientos elevados, cuyo uso es, no obstante, muy escaso en todos los países.

Los niños sujetados por cinturones mal ajustados o sentados en sillas de seguridad para niños mal sujetadas corren el riesgo de salir despedidos del vehículo, sobre todo en caso de vuelco. Aunque no hay datos específicos referidos a los niños, en adultos, el salir despedido del vehículo multiplica por ocho el riesgo de muerte. La mala sujeción de los niños es un problema endémico, y es así que los vuelcos son la causa de $29 \%$ de los accidentes mortales para niños en los EE. UU., aunque solo representan 1 a $2 \%$ de los accidentes.

Las colisiones laterales son peligrosas para los niños. En un estudio, se produjeron lesiones importantes en $41 \%$ de las colisiones laterales, en $15 \%$ de las colisiones frontales y en $3 \%$ de las colisiones por detrás en las que se vieron implicados niños de edad escolar que estaban usando sistemas de sujeción. En otro estudio, la mortalidad de los niños en las colisiones laterales fue de $30 \%$, frente a $17 \%$ en las frontales. Como los sistemas de sujeción no alteran de forma significativa la probabilidad de sufrir lesiones en una colisión lateral ni su gravedad, se recomienda 